$\underline{\text { Review Article }}$

\title{
CORONAVIRUS-A VIRUS IN LEARNING
}

\section{NIHARIKA, B. NIHARIKA, T. AISHWARYA, A. NIKITHA, RABIA BUTOOL, MANAL IBRAHIM, R. DHARAKESWARE}

Department of Biochemistry, St. Francis College for Women, Hyderabad, Telangana, India 500016

Email: niharikapisces.26@gmail.com

Received: 22 Mar 2020, Revised and Accepted: 25 May 2020

\section{ABSTRACT}

Viruses can infect almost all the types of life forms, from animals, plants to microorganisms. They are found in almost every ecosystem on Earth and are the most numerous types of biological entity. The present pandemic on Earth due to SARS COV 2, coronavirus has given a big jolt to the scientific community and created a deep curiosity in us to understand the virus and its interaction biochemically in humans. We did a small project by researching and compiling the information about its outbreak and host-pathogen interactions. To understand this pandemic COVID 19 and the virus, we as students learnt the structural morphology of virus and its role in the host-pathogen interaction. We used several online platforms for our study like PubMed, Scopus, WHO, ICMR and CDC Websites.

Keywords: Coronavirus, Pandemic, Biochemical interactions, Genera

(c) 2020 The Authors. Published by Innovare Academic Sciences Pvt Ltd. This is an open access article under the CC BY license (http://creativecommons.org/licenses/by/4.0/) DOI: http://dx.doi.org/10.22159/ijcpr.2020v12i4.39078. Journal homepage: https://innovareacademics.in/journals/index.php/ijcpr Speedy peer review was done as the subject of the manuscript was related with pandemic

\section{INTRODUCTION}

An acute respiratory infection in domesticated chickens was observed for the first time in 1930s to be caused by the infectious bronchitis virus (IBV) [1]. In 1960s was the first time when human corona virus was discovered [2]. Coronaviruses are from the family Coronaviridae in the order Nidovirales. As far as now, four different genera of Coronavirus have been identified which are Alphacoronavirus, Beta coronavirus, Gamma coronavirus, and Delta coronavirus. Human coronavirus causing COVID 19 is a single-stranded RNA virus of genera Beta coronavirus, named as SARS COV 2.

SARS COV-2 was first identified and isolated from pneumonia patient belonging to WuhanChina, which caused COVID-19 disease in human beings. Coronavirus vary significantly in high risk. According to a report published on 24 Jan 2020, SARS COV-2 virus-infected patients have many common features such as fever, cough, and fatigue, while diarrhoea and dyspnoea were found to be as uncommon features [3, 4]. SARS COV-2 virus was isolated from the Broncho-alveolar lavage fluid of humans in China in 2020. It is also detected in blood samples. Coronavirus presence is also seen in faeces and urine sample of patient, some researchers are working on this for confirmation.

Learning all this from researchers across the globe, we final year students of B. Sc. from Department of Biochemistry, St. Francis College for Women, Hyderabad, also felt the need to explore the biochemical aspect of SARS COV 2.

Cocid-19 disease presentation has a resemblance to severe acute respiratory disease (SARS) that had begun in 2003 in Asia, resulting in a mortality rate of $10 \%$ and middle east respiratory syndrome (MERS) in September 2012 resulting in a 37\%mortality [5].

Coronavirus disease 2019(COVID 19) started in December 2019. It started as a pneumonia outbreak and was reported in Wuhan, China [6]. On December 31, 2019, WHO was informed of cases of pneumonia detected in Wuhan city, China. On January 7, 2020, Chinese authorities had identified the causative virus as SARS CoV-2 causing novel Coronavirus disease (COVID-19). World scientists met at WHO headquarters from 11 to 12 February to assess the current level of knowledge, to agree on critical research questions that needed to be answered urgently and ways to work together to accelerate and fund priority research that can contribute to curtail this outbreak and to prepare for future outbreaks.

COVID-19 was recognised as a pandemic on 11 March 2020 by WHO and countries all over the Globe were alerted with the Infection and mode of transmission along with the strategies for Prevention and Control. Doctors and Researchers outlined that the SARS COV-2 virus affects different people in different ways. COVID-19 is a respiratory disease and most of them will develop mild to moderate symptoms and recover without any special treatment. People who have underlying medical conditions and those who are above $60 \mathrm{y}$ old have a higher risk of developing disease and in the severe case leads to death. It was proposed that people with mild symptoms should self-isolate and contact their medical provider or a COVID-19 information line for advice on testing and referral and people with fever, cough or difficulty in breathing should call their doctor and seek medical attention as soon as possible $[6,7]$.

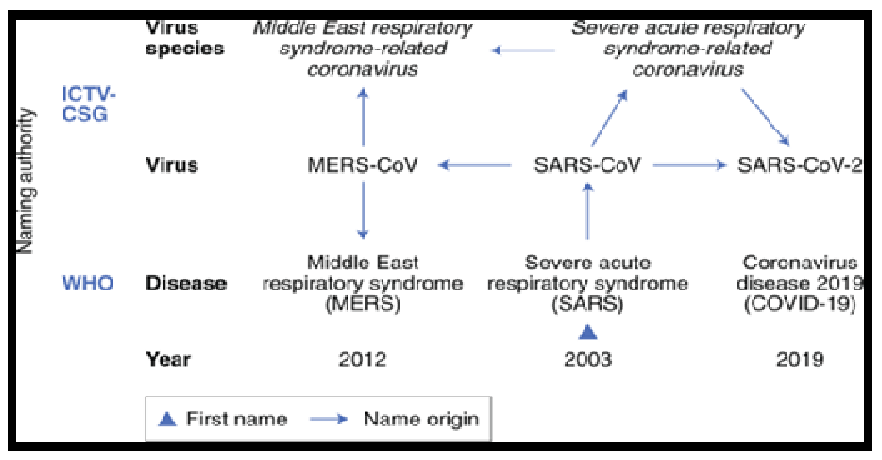

Fig. 1: Outbreak of $\operatorname{cov} 2$ 
SARS COV-2 was found to be transmitting rapidly from one person to another person. It was found that SARS COV-2 has been transmitting through direct contact from people infected with the virus and through indirect contact with various surfaces or objects that were in contact with Covid patients (e. g., stethoscope or thermometer). Generally, the corona virus was spread via airborne zoonotic droplets.

It has been found that the Virus replicates in ciliated epithelium that causes cellular damage and infection at injection site.

These findings led our curiosity further to explore the structure of the virus biochemically and understand its mechanism of action in the host cell. We searched PubMed and websites of CDC, WHO, ICMR and several research articles for our study.

\section{Biochemistry of SARS COV-2}

We learnt from the articles published and researches done recently about the structural morphology of the typical human coronavirus. Though it is understood that the virus has been mutating since the time it was first isolated and many variations have been reported, we are trying to put the general morphology and mechanism of its action.

The coronaviruses are found to be large pleomorphic spherical particles with bulbous surface projections with a diameter of approximately $120 \mathrm{~nm}$. The envelope of the virus in electron micrographs appears as a distinct pair of electron-dense shells [3].

Coronaviruses are large, enveloped, positive single-stranded RNA viruses. They have a genome ranging from 27 to $32 \mathrm{~kb}$, which is largest genome among all RNA viruses. The genome is arranged as a packed helical capsid formed by the nucleocapsid protein $(\mathrm{N})$ which is then surrounded by an envelope. There are three structural proteins associated with viral envelope which are: The membrane protein (M) and the envelope protein (E) are involved in virus assembly, and the spike protein $(\mathrm{S})$ mediates virus entry into host cells. The viral envelope is composed of a lipid bilayer where the membrane (M), envelope (E) and spike (S) structural proteins are anchored. A subset of coronaviruses (specially the members of beta coronavirus subgroup A) are known to have a shorter spike like surface protein known as haemagglutinin esterase (HE).

Multiple copies of nucleocapsid (N) protein are bound to a positive single-stranded RNA genome in a continuous beads-on-a-string type conformation forming a nucleocapsid inside the envelope [8]. The genome has a 5'methylated cap and a 3' polyadenylated tail.

When the virus is outside the cell the lipid bilayer, membrane proteins, and nucleocapsid protects the virus. The envelope glycoproteins are responsible for attachment to the host cell and carry the main antigenic epitopes, particularly the epitopes recognized by neutralizing antibodies. OC43 also possesses a hemagglutinin, Hemagglutinin Esterase (HE) and Nucleocapsid (N) protein [9]. $\mathrm{HE}$ is a protein that is present only in some beta coronaviruses whereas all envelope proteins and $\mathrm{N}$ protein are present in all the virions. In addition to that, it is thought that the virus particles are huddled together owing to the interaction between these proteins.

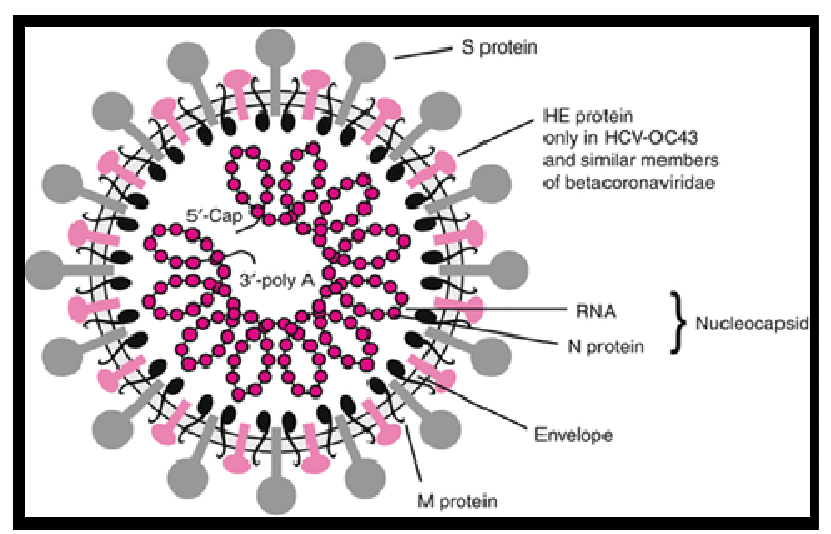

Fig. 2: Structure of COV 2

S Glycoproteins are located outside the virions. The S proteins form homotrimers. These proteins are binding to a virion membrane through the $\mathrm{C}$ terminal transmembrane regions interacting with $\mathrm{M}$ proteins. There are three transmembrane regions found in $\mathrm{M}$ Glycoproteins and they are glycosylated in the Golgi apparatus. This modification of the M protein is crucial for the virion to fuse into the cell and to make protein antigenic. The $M$ protein plays a key role in regenerating virions in the cell. The $\mathrm{N}$ protein binds to genomic RNA and $\mathrm{M}$ protein, forming a complex which triggers the formation of interacting virions in endoplasmic reticulum-Golgi apparatus intermediate compartment (ERGIC) with this complex [10].

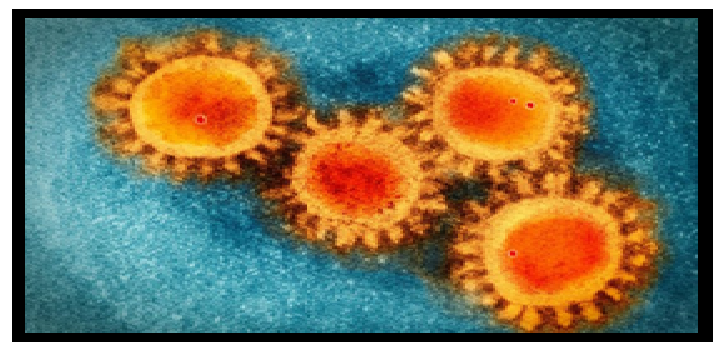

Fig. 3: Radiological image of COV 2 in Patient's sample

E Glycoproteins are small proteins composed of approximately 76 to 109 amino acids. There are around 30 amino acids in the E proteins
(N-terminus), which allows attachment to the membrane of viruses. There is a critical role which is taken up by coronavirus $\mathrm{E}$ in 
assembly and morphogenesis of virions within the cell. As N protein is localized in both the replication/transcriptional regions of coronaviruses and ERGIC regions where the virus is collected, it has a great role in virion structure, replication and transcription of coronaviruses. Receptor binding and membrane fusion are the initial and critical steps in the coronavirus infection cycle; they also serve as primary targets for human interventions.

There are two kinds of coronaviruses that recognize a zinc peptidase angiotensin-converting enzyme 2(ACE2) which are alpha coronavirus (HCov-NL63) and beta coronavirus (SARS COV). It was suggested that angiotensin receptor one blockers such as losartan could be used to reduce aggressiveness and mortality from SARS COV-2 as it could resist mutations [10]. This observation is because angiotensin-converting enzyme 2 serves as the binding site for SARS COV-2.

It was found by the scientists that the Receptor Binding Domain of SARS COV-2has few spike proteins that have evolved to target a molecular feature on the outside of human cells called ACE2, a receptor that is involved in regulating blood pressure. The scientists concluded that SARSCOV-2 is a natural selection and not a product of genetic engineering as its spike protein is very effective in binding the human cells. It is also found by researchers that the SARS-COV-2 backbone differed substantially from those of already known coronaviruses and mostly resembled related viruses found in bats and pangolins providing evidence for its natural evolution. In a scenario the virus has evolved to its current pathogenic state through natural selection in some non-human host and that was later passed to humans by the intermediate host. As the SARS COV-2 is very much like bat coronaviruses scientist proposed bats as the most likely reservoir, but then there is no evidence regarding direct bat-human transmission, suggesting there was an intermediate host involved in the transmission.

When the virus enters, $\mathrm{S} 1$ binds to a receptor on the host cell surface for viral attachment, and S2 fuses the host and viral membranes, which allows viral genomes to enter host cells [11].

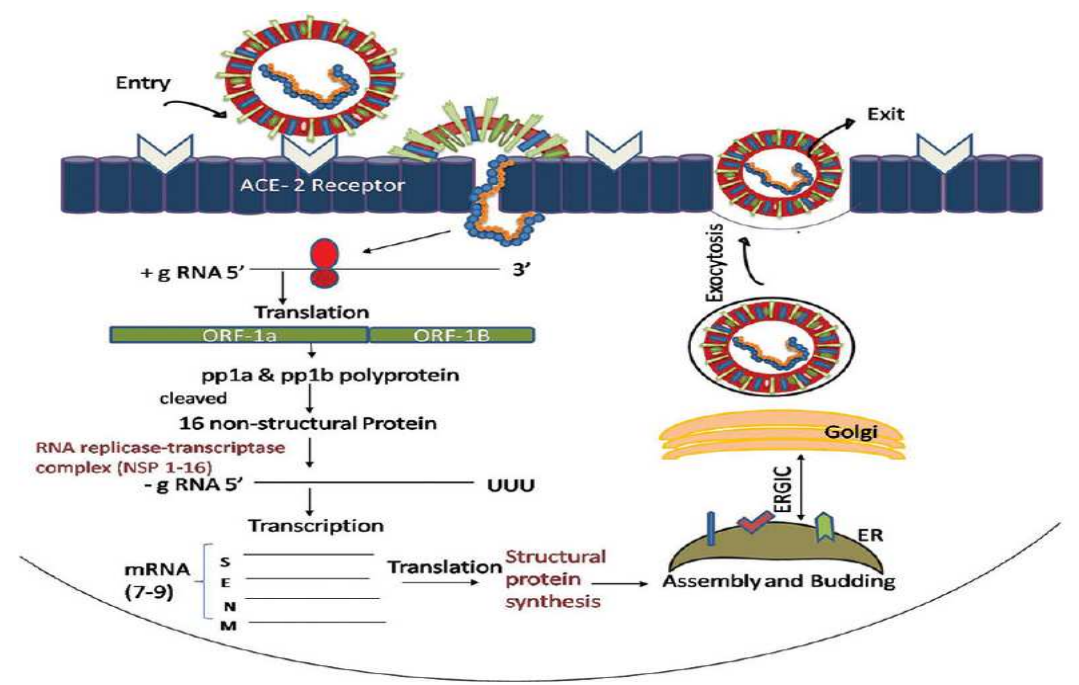

Fig. 4: The life cycle of COV in host cells. The $S$ proteins of COV binds to cellular receptor angiotensin-converting enzyme 2 (ACE2) which is followed by entry of the viral RNA genome into the host cell and translation of structural and nonstructural proteins (NSP) follows. Open reading framesORF1a and ORF1ab are translated to produce pp1a and pp1ab polyproteins, which are cleaved by the proteases that are encoded by ORF1a to yield 16 non-structural proteins. This is followed by assembly and budding into the lumen of the ERGIC (Endoplasmic Reticulum Golgi Intermediate Compartment). Virions arereleased from the infected cell by exocytosis. S: spike, E: envelope, M: membrane, N: nucleocapsid. PP: polyproteins, ORF: Open reading frame, COV: coronavirus [12]

The life cycle (fig. 4) shows the growth and proliferation of virus in the host. This further leads to presentation of symptoms in the host whose immunity is not able to curb the virulence of virus. The people with comorbidity and elderly population are most affected and become symptomatic. Around twenty percent of these symptomatic patients need vigilant monitoring in hospitals. Worldwide countries are reporting and updating the infection data. The challenge is to diagnose infected people on time so that they can be isolated and spread of the disease COVID 19 can be avoided.

\section{CONCLUSION}

As Final year B. Sc. students, we learnt the basic structural aspects and mechanism of action of the Coronavirus in the host cell through our study. Though the virus is a mutating virus we tried to understand the basic structural morphology of the novel Coronavirus in this study. The real challenge that we understand today is to timely diagnose the positive cases as the incubation period is seven to fourteen days and many a times, the infection is asymptomatic. World over countries are working in collaboration with each other, to develop better and faster diagnostic methods to detect the presence of COVID 19 in population. This will help in isolating the infected person early and preventing the further spread of the infection. RandD of pharmaceutical industry is focusing on designing and developing the therapeutic measures along with vaccination. Many countries, including United States and India are rigorously working on vaccine development. Some light of success is seen with the start of Clinical trials. Drug discovery for effective treatment is also one challenge that countries are facing. This pandemic of $21^{\text {st }}$ century has brought humanity on planet Earth together, breaking the boundaries. We as students, have a long way and would like to contribute to the welfare of the health of mankind and environment protection.

\section{ACKNOWLEDGEMENT}

We would like to thank Dr Dipti Soni Jaipuriar, all the faculty members \& HOD of the Department of Biochemistry Ms P Kanchana, St. Francis College , Hyderabad, for their motivation and support for this project work. We extend our sincere gratitude towards our principal Sr. Sandra Horta St. Francis College for Women, Hyderabad for providing us with this opportunity. We would also like to thank our friends Dipali Kumari and K.Pavani for supporting us throughout the work.

\section{FUNDING}

Nil

\section{AUTHORS CONTRIBUTIONS}

All the authors have contributed equally. 


\section{CONFLICT OF INTERESTS}

The authors declare no conflict of interest, financial or otherwise.

\section{REFERENCES}

1. Neuman BW, Kiss G, Kunding AH, Bhella D, Baksh MF, Connelly $\mathrm{S}$, et al. A structural analysis of $\mathrm{M}$ protein in coronavirus assembly and morphology. J Struct Biol 2011;174:11-22.

2. Lissenberg A, Vrolijk MM, van Vli, Langereis MA, de Groot Mijnes JD, Rottier PJ, et al. Luxury at a cost? Recombinant mouse hepatitis viruses expressing the accessory hem agglutinin esterase protein display reduced fitness in vitro. J Virol 2005;79:15054-63.

3. Lai MM, Cavanagh D. The molecular biology of coronaviruses. Adv Virus Res 1997;48:1-100.

4. De Haan CA, Rottier PJ. Molecular interactions in the assembly of coronaviruses. Adv Virus Res 2005;64:165-230.
5. Zhu N, Zhang D, Wang W, Li X, Yang B, Song J, et al. A novel coronavirus from patients with pneumonia in China, 2019. New Engl J Med 2020;382:727-33.

6. Kahn JS, McIntosh K. History and recent advances in corona virus discovery. Pediatric Inf Disease J 2015;24 (11 Suppl):S223-27.

7. The Editorial Board. Is the world ready for the coronavirus? distrust in science and institutions could be a major problem if the outbreak worsens. The New York Times; 2020.

8. Li F, Li W, Farzan M, Harrison SC. Structure of SARS coronavirus spike receptor-binding domain complexed with receptor. Science 2020;309:1864-68

9. Doucleef M. Scientists go deep on genes of SARS-like virus. Associated Press. Archived from the original; 2012.

10. Fang Li. Structure, function, and evolution of coronavirus spike proteins. Annu Rev Virol 2016;3:237-61.

11. X Songs Jiang. Viruses 2019, emerging microbes and infections, the Economist; 2012.

12. Prajapat M, Sarma P, Shekhar N, Avti P, Sinha S, Kaur H, et al. Drug targets for corona virus: a systematic review. Indian J Pharmacol 2020;52:56-65. 